\title{
CONTRIBUTION OF COACHING SKILLS TO LEADERSHIP
}

\section{Slavica Squire}

PhD candidate, Singidunum University, Institute for Neuro-Linguistic Programming, Belgrade, Serbia

\begin{abstract}
:
Coaching uses a range of skills to help individuals and teams shift their perspective in order to discover different approaches that can be used to achieve their goals. It supports individuals and teams in using their own resources, options and skills supporting any endeavor. Quality of leadership is perceived as critical to the success of any organization. In the modern business world, leaders more and more often rely on coaching skills to enable their employees overcome challenges they face. The results of the research presented in this paper show that in most of the organizations from which the participants came there is no coaching support of employees, while the research participants found that coaching education and coaching skills improved their leadership, communication and interpersonal relationships and contributed to their success.
\end{abstract}

\section{Keywords:}

coaching, organizations, leadership, skills.

\section{INTRODUCTION}

Coaching is a frequent topic in management literature and among the most frequently discussed leadership skills (Hunt \& Weintraub, 2004). It has been defined in a number of ways and in general it is a process in which a person's resources and competencies are developed. Managerial coaching aims to correct employee behaviors and thus improve organization's results and retain employee in the organization (Gilley et al, 2010, Tanskanen et al, 2019).

Leaders are increasingly being called upon to coach employees as the benefits of coaching become more and more evident. "Managerial coaching" can take place in formal coaching sessions or informally, on an ad hoc basis (Milner et al, 2018). In using key coaching skills managers try to enable employees to work out solutions for their own issues by themselves instead of expecting managers to do so on their behalf. When managers role model coaching behaviors, it is more likely that employees will establish the same kind of behavior with clients, and thus establish a better client relationship, which can lead to improved personal satisfaction and higher performance.

\section{REVIEW OF THE LITERATURE}

Correspondence:

Slavica Squire

e-mail:

slavica@nlpinstitut.com
The four key coaching competencies are support, listening, feedback and asking precise questions (Hall, 2015).

Coaching is supporting a person to understand and transform personal situation in accordance with the person's desire. Rapport as one of the key competencies necessary for coaching is establishing a close relationship with a client, so that the client can feel safe, 
understood and respected in order to accept challenges, receive useful feedback, change and transform (Hall, 2015). The aim of a coach is to establish an environment with as much safety, warmth and empathic understanding as possible (Hayes, 2006, Gilley et al, 2010, Squire, 2016a, Squire, 2017b).

Coaching as any other engaged and respectful communication starts with active and engaged listening and it unveils deep structure behind the content. Active listening is important because coaching mostly depends on unambiguous communication and good relationship. That is listening and reaction to what and how a client speaks, which leads to better mutual understanding and relationship (Haneberg, 2016, Gilley et al, 2010).

Feedback functions as a mirror - it reflects what and how we do something. It is an important indicator of the quality of interpersonal relationships and achievements of teams, valuable for further progress and improvement. Feedback requires expertise. It is about issues that may be addressed and it has a structure (Rogers, 2012, Gilley et al, 2010).

Effective questions in coaching provoke thinking and raise client's self-awareness. They make client stick to the agenda, they go beyond by asking for discovery and encourage the coachee to take responsibility for himself (Haneberg, 2016, Gilley et al, 2010). Questions are tools which activates internal processes since the human mind has defense mechanisms to figh against arguments and advice.

The aim of the research presented in this paper was to analyze coaching skills in managerial practice and the influence of coaching skills on leadership, communication and interpersonal relationships in organizations, as well as assess the contribution of competencies of coach on the personal success of managers.
An imperative part of building any practice is measuring it effect or what success practicing it looks like. There are no measures that can tell if coaching efforts have been success. Some experts say that success can be measured by mini surveys designed to determine the degree of progress against goals over some period or some measurable change in leadership behavior (Haneberg, 2016). As all the participants of the research presented in this paper are performers judging by their educational background and their job titles, the research focused on their results and impact of coaching training on their success.

\section{METHODOLOGY}

Thirty persons participated in the research. All of them are managers of various sectors of public enterprises, private and international companies and all of them attended the Coaching Academy and acquired the researched competencies.

The sample consists mostly of women (73.3\%). The dominant age group is from $41-50$ years (60\% of participants). As far as education is concerned, $50 \%$ of the participants hold a master's degree. The average length of service is 19.7 years, and most of the participants work in private companies (43.3\%). The research was conducted using a Google Forms questionnaire. Detailed characteristics are presented in Table 1.

Table 1. Research sample characteristics $(\mathrm{N}=30)$

\begin{tabular}{ll}
\hline SAMPLE CHARACTERISTICS & \\
\hline Description & Percentage \\
\hline Respondent's gender & 26,7 \\
\hline Male & 73.3 \\
\hline Female & 30 \\
\hline Respondent's Age & 60 \\
\hline $31-40$ & 10 \\
\hline $41-50$ & \\
\hline $51-60$ & 36.7 \\
\hline Educational background & 50 \\
\hline College & 13.3 \\
\hline Master's degree & \\
\hline Professional master & 26.7 \\
\hline Type of company & 43.3 \\
\hline Public enterprise & 23.3 \\
\hline Private company & 6.7 \\
\hline International company & \\
\hline Other
\end{tabular}


The instrument used for collecting data was a questionnaire consisting of several parts. The first contained questions regarding sociodemographic characteristics of the participants (gender, age, education) and information regarding the type of the organization they were employed by, the length of service, occupation etc.

The second part contained questions about the most important coaching skills for the participants, the most frequently used competence and the least used competence. Four answers were offered for all three questions: listening, support, asking precise questions and feedback.

In the third part of the questionnaire participants rated usefulness of the skills on Likert scale (1- not useful at all, 2 - relatively useless, 3 - unclear, 4 - relatively useful and 5 - completely useful) in specific activities: motivating coworkers, collecting precise information, unambiguous communication, better understanding, initiating necessary change, positive influence in dialogues, personal success, personal disburdening, releasing tensions, improvement of interpersonal relations.

The last part measured influence of coaching training and coaching skills on the improvement of leadership skills, better communication, the improvement of managerial skills,

the improvement of interpersonal relationships, the improvement of the skills necessary for coworkers' motivation, rising probability of getting promoted, stress reduction, personal development, personal success and personal satisfaction. Responses were measured on the scale from 1 to 5 ( 1 - no influence, 2- partially without influence, 3- undetermined, 4- partial influence, 5 - complete influence).

\section{RESULTS AND DISCUSSION}

Table 1. reports that almost three quarters of the participants were women, and that most of the participants were from 41 to 50 years old. All the respondents are performers generally, which is why they put effort in developing different skills, which in turn results in success at work. The largest number of respondents work in private companies.

Chart 1. reports that asking precise questions is most frequently used skill with the best results for managers. Respondents perceive listening as somewhat less important, while feedback and support follow them and are almost of equal importance.
Chart 1. Most useful coaching skill

Most useful skills

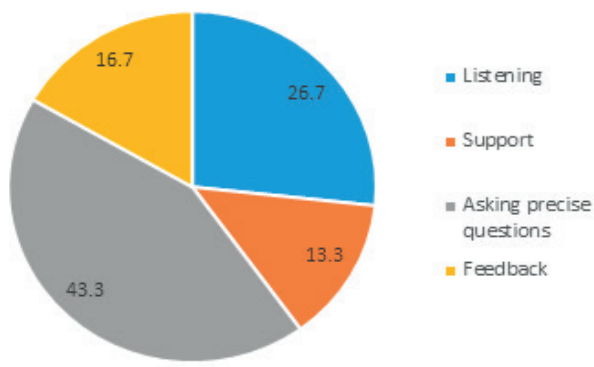

Support and asking precise questions are used equally. Listening follows them, while feedback as the most complex competence is least used (Chart 2).

Chart 2. Most frequently used competencies Most frequently used competencies

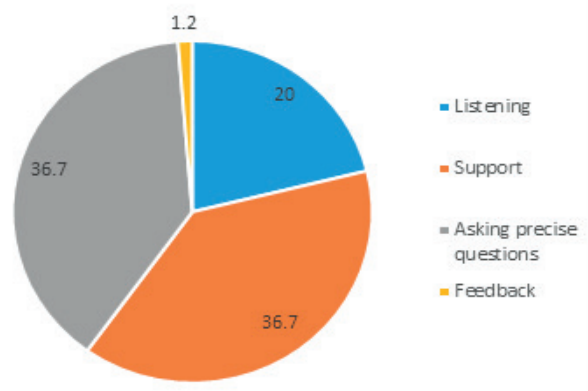

Respondents found that feedback is the most difficult competence since it is a complex skill which requires a good state of coach. It is necessary to give feedback as soon as possible and at the same time be emotionally balanced and capable of making a good judgement. The competence requires to give an employee some feedback and follow up on it by making suggestions on how to further improve some behavior or state in the future (Chart 3.).

Chart 3. Most difficult and least used competencies

The most difficult and the least used competency

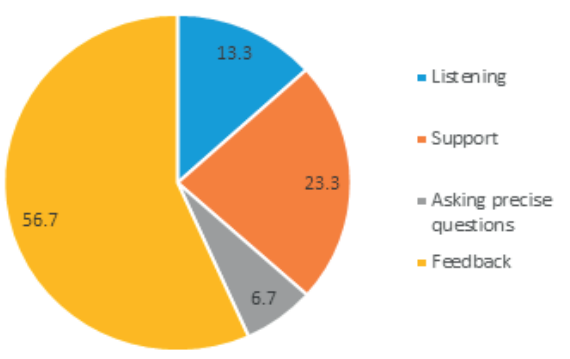




\subsection{Results of descriptive statistics}

Respondents rated usefulness of listening skill in managerial practice for various activities on a 5-point Likerttype scale from not useful at all to completely useful.
The results are presented in Table 2. and ranked from those activities for which listening is most useful to the ones they considered to be least influenced by listening skill.

Table 2. Perception of importance of listening

\begin{tabular}{lll}
\hline Listening in managerial practice is useful for: & $\begin{array}{c}\text { Mean value of } \\
\text { answers }\end{array}$ & Average deviation \\
\hline Collecting precise information & 4.67 & 0.661 \\
\hline Unambiguous communication & 4.47 & 0.73 \\
\hline Better understanding & 4.47 & 0.819 \\
\hline Improvement of interpersonal relationships & 4.4 & 0.77 \\
\hline Positive influence in dialogue & 4.3 & 0.837 \\
\hline Initiating of necessary change & 4.1 & 0.923 \\
\hline Personal success & 4.07 & 0.907 \\
\hline Motivation of coworkers & 3.97 & 0.85 \\
\hline Releasing tension & 3.67 & 1.061 \\
\hline Personal disburdening & 3.53 & 1.106 \\
\hline
\end{tabular}

Source: Research

Respondents indicated that listening is most important for collecting precise information, unambiguous communication and better understanding. The highest percentage of participants uses this skill in all types of communication with coworkers and employees.
Using the same 5-point scale respondents were asked to rate the significance of providing support in all business activities, and they found it to be the most important for influencing coworkers in dialogue, initiating necessary change, motivation of coworkers and improvement of interpersonal relationships.

Table 3. Perception of importance of providing support

\begin{tabular}{lll}
\hline $\begin{array}{l}\text { Providing support in managerial practice is } \\
\text { useful for: }\end{array}$ & $\begin{array}{c}\text { Mean value of } \\
\text { answers }\end{array}$ & Average deviation \\
\hline Positive influence in dialogue & 4.70 & .596 \\
\hline Initiating necessary change & 4.60 & .621 \\
\hline Motivation of coworkers & 4.60 & .675 \\
\hline Improvement of interpersonal relationships & 4.60 & .814 \\
\hline Personal success & 4.37 & .765 \\
\hline Better understanding & 3.90 & .923 \\
\hline Releasing tension & 3.87 & .847 \\
\hline Unambiguous communication & 3.67 & 1.278 \\
\hline Personal disburdening & 3.57 & .820 \\
\hline Collecting precise information & 3.50 & .844 \\
\hline
\end{tabular}

Source: Research 
Asking precise questions is particularly important for collecting precise information, unambiguous communication and better understanding (Table 4).
Giving and receiving feedback is particularly useful for better understanding, improvement of interpersonal relationships and motivation of coworkers (Table 5).

Table 4. Perception of significance of asking precise questions

\begin{tabular}{lll}
\hline $\begin{array}{l}\text { Asking precise questions is particularly } \\
\text { important for: }\end{array}$ & $\begin{array}{c}\text { Mean value of } \\
\text { answers }\end{array}$ & Average deviation \\
\hline Collecting precise information & 4.70 & .702 \\
\hline Unambiguous communication & 4.57 & .728 \\
\hline Better understanding & 4.50 & .861 \\
\hline Personal success & 4.37 & .928 \\
\hline Improvement of interpersonal relationships & 4.23 & .935 \\
\hline Initiating necessary change & 4.17 & .986 \\
\hline Positive influence in dialogue & 4.13 & .860 \\
\hline Personal disburdening & 3.87 & 1.074 \\
\hline Motivation of coworkers & 3.87 & 1.008 \\
\hline Releasing tension & 3.77 & 1.006 \\
\hline
\end{tabular}

Source: Research

Table 5. Perception of importance of giving and receiving feedback

\begin{tabular}{llc}
\hline $\begin{array}{l}\text { Asking precise questions is particularly } \\
\text { important for: }\end{array}$ & $\begin{array}{c}\text { Mean value of } \\
\text { answers }\end{array}$ & Average deviation \\
\hline Collecting precise information & 4.70 & .702 \\
\hline Unambiguous communication & 4.57 & .728 \\
\hline Better understanding & 4.50 & .861 \\
\hline Personal success & 4.37 & .928 \\
\hline Improvement of interpersonal relationships & 4.23 & .935 \\
\hline Initiating necessary change & 4.17 & .986 \\
\hline Positive influence in dialogue & 4.13 & .860 \\
\hline Personal disburdening & 3.87 & 1.074 \\
\hline Motivation of coworkers & 3.87 & 1.008 \\
\hline Releasing tension & 3.77 & 1.006 \\
\hline
\end{tabular}

Source: Research 
Respondents rated influence of coaching training and practicing coaching skills on various aspects of their jobs on the same 5-point Likert-type scale ranging from no influence at all to complete influence useful. The results are presented in Table $5 \mathrm{a}$.

Table 5a. Influence of coaching education and practicing coaching skills

\begin{tabular}{lll}
\hline $\begin{array}{l}\text { Influence of coaching education and } \\
\text { practicing coaching skills on: }\end{array}$ & $\begin{array}{c}\text { Mean value of } \\
\text { answers }\end{array}$ & Average deviation \\
\hline Personal development & 4.77 & .626 \\
\hline Personal satisfaction & 4.77 & .568 \\
\hline Better communication in general & 4.73 & .583 \\
\hline Personal success & 4.70 & .651 \\
\hline Improvement of manager's skills & 4.67 & .606 \\
\hline Improvement of leadership skills & 4.60 & .675 \\
\hline Improvement of interpersonal relationships & 4.53 & .681 \\
\hline Improvement of skills necessary for motivating & 4.47 & .724 \\
\hline coworkers & 4.40 & 1.029 \\
\hline Stress reduction & 4.10 & \\
\hline An increase in the probability of getting promoted & & \\
\hline
\end{tabular}

Source: Research

It is evident that respondents highly rated influence of coaching training and coaching skills on all aspects of their jobs and in particular personal development, personal satisfaction, better communication in general and personal success. At the same time, they find that an increase in the probability of getting promoted is least influenced.

\subsection{Analysis of variance - ANOVA test}

ANOVA test was used in order to establish the difference in answers between respondents of different educational background, age groups and from different types of organizations (public enterprise, private or international company). The results imply that as far as educational background is concerned, there is a difference only in the perceived significance of asking precise questions in order to motivate coworkers. LSD Post Hoc test demonstrates that professional masters perceive asking precise questions as less useful for motivation of coworkers than masters and college graduates.

As far as age of respondents is concerned, several differences were noticed:

- Respondents of different age groups perceive importance of providing support in everyday managerial practice in order to influence a person in dialogue differently ( $\mathrm{F}=3.881, \mathrm{p}=.003)$. LSD Post Hoc test shows that respondents from age group 51-60 perceive providing support in managerial practice as less useful for positive influence in dialogue than respondents from age groups 41-50 and 31-40.

- Respondents of different age groups perceive differently the significance of asking precise questions in order to collect precise information $(\mathrm{F}=4.502, \mathrm{p}=.021)$, for better understanding $(\mathrm{F}=4.091, \mathrm{p}=.028)$, positive influence in dialogue $(\mathrm{F}=3.830, \mathrm{p}=.034)$, releasing tension $(\mathrm{F}=3.433, \mathrm{p}=.027)$ and improvement of interpersonal relationships $(\mathrm{F}=3.388, \mathrm{p}=.049)$. LSD Post Hoc test shows that respondents from age group 51-60 perceive asking precise questions as less important for collecting precise information, better understanding, positive influence in dialogue, releasing tension and improvement of interpersonal relationships than those from age groups 41-50 and 31-40.

- Respondents from different age groups differ according to their perception of the influence of giving and receiving feedback on better communication $(\mathrm{F}=3.323, \mathrm{p}=.051)$, positive influence in a dialogue $(\mathrm{F}=4.819, \mathrm{p}=.016)$, personal disburdening $(\mathrm{F}=9.720, \mathrm{p}=.001)$, releasing tension $(\mathrm{F}=11.536, \mathrm{p}=.000)$, and improvement of interpersonal relationships $(\mathrm{F}=6.217, \mathrm{p}=.006)$. The respondents from the age group 51-60 perceive giving and receiving feedback in order to improve interpersonal relationships as less important than those from the age groups 4150 and 31-40. On the other hand, respondents 
from the age group 41-50 perceive giving and receiving feedback as important for unambiguous communication, positive influence in dialogue and personal disburdening and releasing tension in managerial practice.

- Respondents of different age groups perceive differently the influence of coaching training and practicing coaching skills on better communication in general $(\mathrm{F}=6.217, \mathrm{p}=.006)$, improvement of leadership skills $(\mathrm{F}=6.217, \mathrm{p}=.006)$, stress reduction $(\mathrm{F}=6.217, \mathrm{p}=.006)$ and personal satisfaction $(\mathrm{F}=6.217, \mathrm{p}=.006)$. The respondents from the age group 41-50 perceive coaching training and practicing coaching skills to be influencing better communication in general more than respondents from the age group 5160. The respondents from the age group 51-60 indicated that coaching training and practicing coaching skills influence improve managerial skills, reduce stress and improve personal satisfaction less than younger respondents.

There are significant differences in the answers of the participants from different types of companies, especially between those from public enterprises on the one hand and those from private and international companies on the other.

- Respondents from different types of companies differ according to their perception of usefulness of listening in managerial practice in order to collect precise information $(\mathrm{F}=4.383, \mathrm{p}=.023)$, to achieve unambiguous communication $(\mathrm{F}=3.580$, $\mathrm{p}=.042)$, personal success $(\mathrm{F}=3.570, \mathrm{p}=.043)$ and to improve interpersonal relationships $(\mathrm{F}=7.752$, $\mathrm{p}=.002$ ). The results of LSD Post Hoc test show that the participants from public enterprises find listening in order to collect precise information and to improve interpersonal relationships less important than the respondents from private and international companies. They also find it less important for unambiguous communication, as well as for personal success.

- The perception of usefulness of providing support in managerial practice in order to motivate coworkers $(\mathrm{F}=5.058, \mathrm{p}=.014)$, to make positive influence in dialogue $(\mathrm{F}=4.992, \mathrm{p}=.015)$, and to improve interpersonal relationships $(\mathrm{F}=4.932$, $\mathrm{p}=.016$ ) differs depending on type of company.

- The results of LSD Post Hoc test show that employees from public enterprises perceive providing support in managerial practice as less useful for motivation of coworkers, positive influence in dialogue and improvement of interpersonal relationships than the employees from private and international companies.
- The perception of usefulness of asking precise questions in order to achieve positive influence in dialogue $(\mathrm{F}=6.852, \mathrm{p}=.008)$ is different in the case of employees from different types of companies. The employees from public enterprises find this competence less useful than the employees from international companies.

- Participants from different types of companies perceive differently the usefulness of giving and receiving feedback in order to motivate coworkers $(\mathrm{F}=6.852, \mathrm{p}=.008)$, to collect precise information $(\mathrm{F}=6.852, \mathrm{p}=.008)$ and to achieve positive influence in dialogue $(\mathrm{F}=6.852, \mathrm{p}=.008)$. LSD Post Hoc test indicates that those from public enterprises find it less useful than those from international companies.

- There are also differences in the perception of the influence of coaching training and practicing coaching on the improvement of leadership skills $(\mathrm{F}=5.050, \mathrm{p}=.014)$, better communication in general $(\mathrm{F}=4.992, \mathrm{p}=.015)$, and better motivation of coworkers $(\mathrm{F}=7.549, \mathrm{p}=.025)$. The respondents from public enterprises find them less useful than those from private and international companies.

\subsection{Pearson's correlation coefficient}

Pearson's correlation coefficient was applied to analyze the covariance of length of service and significance of the selected skills in managerial practice for the analyzed issues. The results show that there is no correlation between the length of service and significance of providing support for the analyzed topics. On the other hand, the length of service was closely connected to the significance of giving and receiving feedback and asking precise questions. Pearson's correlation coefficient implies that significance of providing support in order to achieve personal success and personal disburdening rises with longer service of respondents. 
Table 6. Correlation of length of service with significance of providing support in managerial practice

\begin{tabular}{ll}
\hline & Length of service \\
\hline Motivation of coworkers & -0.183 \\
\hline Collecting precise information & 0.093 \\
\hline Unambiguous communication & 0.17 \\
\hline Better understanding & 0.011 \\
\hline Initiating necessary change & 0.01 \\
\hline Positive influence in dialogue & 0.057 \\
\hline Personal success & $.390^{\star}$ \\
\hline Personal disburdening & $.393^{\star}$ \\
\hline Releasing tension & 0.3 \\
\hline Improvement of interpersonal relationships & 0.145 \\
\hline
\end{tabular}

Source: Research

Apart from that, perceived importance of giving and receiving feedback rises with longer service in case of initiating necessary change, better understanding, personal success and releasing tension.

Table 7. Correlation of length of service and perception of significance of giving and receiving feedback in managerial practice

\begin{tabular}{lc}
\hline & Length of service \\
\hline Motivation of coworkers & 0.237 \\
\hline Collecting precise information & 0.119 \\
\hline Unambiguous communication & 0.339 \\
\hline Better understanding & $.447^{\star}$ \\
\hline Initiating necessary change & $.383^{\star}$ \\
\hline Positive influence in dialogue & 0.323 \\
\hline Personal success & $.430^{\star}$ \\
\hline Personal disburdening & 0.229 \\
\hline Releasing tension & $.423^{\star}$ \\
\hline Improvement of interpersonal relationships & 0.035
\end{tabular}

Source: Research

\subsection{Discussion}

Respondents found that asking precise questions is the most useful coaching skill. They found listening, giving and receiving feedback and support less useful probably because these are more demanding coaching skills that require coaching experience in order to be put into practice. The results of the survey also show that they use support and asking precise question most often, somewhat less listening, and that they give and receive feedback least probably because it is the most demanding skill.

Managers find listening as a completely useful competence for collecting precise information, unambiguous communication and better understanding, while a small number of respondents found it relatively useless for motivation and better understanding. Listening is least important for personal disburdening, releasing tension and motivation of coworkers, which leads to the conclusion that managers probably need to develop this competence through its active application in everyday business environment in order to fully develop it.
Respondents found providing support completely useful for motivation of employees and relatively useful for better understanding. The highest importance of providing support is evident in the case of a positive influence in dialogue, initiating necessary change, motivation of coworkers and improvement of interpersonal relationships.

Respondents from the age group 51-60 perceive providing support as less important for achieving positive influence in dialogue. Participants from public enterprises perceive providing support in order to motivate coworkers, achieve positive influence in dialogue and improve interpersonal relationships as less important. Perceived significance of providing managerial support in order to achieve personal success and personal disburdening rises with longer service.

The respondents from the age group 51-60 perceive asking precise questions in order to collect precise information, achieve better understanding and positive influence in dialogue, release tension and improve interpersonal relationships as less important than the respondents 
from the age groups 41-50 and 31-40. The respondents from public enterprises perceive asking precise questions in order to achieve a positive influence in dialogue as less important than the respondents from private and international companies. There is a positive correlation between the length of service and perceived significance of asking precise questions.

As far as asking precise questions is concerned, respondents perceive it as completely useful for all types of communication with coworkers and employees and most valuable for collecting precise information, unambiguous communication, better understanding.

Most respondents perceive giving and receiving feedback as completely useful for various types of communication and situations, from motivation to better understanding, and some of them perceive it as relatively useful, while almost no one rated the skill as not useful at all. Respondents find giving and receiving feedback particularly useful for better understanding, improvement of interpersonal relationships and motivation of coworkers in managerial practice. The respondents from the age group 51-60 perceive giving and receiving feedback as less useful for the improvement of interpersonal relationships in managerial practice than those from the age groups 41-50 and 31-40. On the other hand, the respondents from the age group 41-50 perceive giving and receiving feedback in managerial practice important for unambiguous communication, positive influence in dialogue, personal disburdening and releasing tension more than those from other age groups. The respondents from public enterprises perceive giving and receiving feedback as less useful for motivation of coworkers and collecting precise information than those from private and international companies. The length of service correlates positively with perceived significance of giving and receiving feedback. The perceived significance of giving and receiving feedback in order to initiate necessary change, for better understanding, personal success and releasing tension rises with longer service.

\section{CONCLUSION}

The research indicates that managers believe that coaching training and practicing coaching improved their leadership skills. The perception of usefulness of coaching training and practicing managerial coaching is influenced both by the type of organization respondents come from and by the age of managers. The managers from private and international companies and those below the age of 51 perceive managerial coaching skills as more useful for all types of the researched activities and for all the researched issues. There is a positive correlation between the length of service of respondents and their perception of significance of coaching skills.
Significance of providing support in some aspects of managers' jobs rises with the length of service of respondents.

Findings of the research suggest that managerial coaching improves leadership skills, communication and interpersonal relationships and contributes to managers' success. Given the increasingly competitive business environment, coaching skills may provide a needed advantage.

\section{LITERATURE}

Gilley, A., Gilley J. W., Kouider E. (2010) Characteristics of Managerial Coaching. Performance Improvement Quarterly, 23(1), 53-70

Hall, M. L. (2015) Coaching Mastery, International Society of Neuro-Semantics.

Haneberg, L. (2016) Coaching Basics 2nd edition. Association for Talent Development.

Hayes, P. (2006) NLP Coaching. Maidenhead, England: McGraw-Hill Education.

Hunt, J. M., \& Weintraub J. R. (2004). Learning developmental coaching. Journal of Management Education, 28(1), 39-61.

Milner, J., McCarthy, G., Milner, T. (2018) Training for the coaching leader: how organizations can support managers, Journal of Management Development, Vol. 37 Issue: 2, pp. $188-200$

Rogers, J. (2012) Coaching Skills : A Handbook (Vol. $3^{\text {rd }}$ ed). Maidenhead: McGraw-Hill Education.

Squire, S. (2016) Kako postati Life Coach?, e-knjiga, NLP Institut \& Coaching akademija Slavica Squire, Beograd.

Squire, S. (2017) Professional Coaching, skripta za Coaching Akademiju, NLP Institut \& Coaching akademija Slavica Squire, Beograd.

Tanskanen, J., Mäkelä, L., Viitala, R. (2019) Linking Managerial Coaching and Leader-Member Exchange on Work Engagement and Performance, J Happiness Stud, 20: $1217-1240$ 